\title{
TÓPICOS SOBRE A GLOBALIZAÇÃO
}

\author{
Cidoval Morais*
}

\section{INTRODUÇÃO}

(uma quase justificativa)

Os estudos sobre globalização são recentes. O termo sociedade global foi cunhado pela primeira vez no início da década de 50 por Gurvitch em "Les types de société globale" e propunha compreender os fenômenos sociais que englobam e ultrapassam os grupos, as classes sociais e até mesmo os Estados. No seu entender, a sociedade global seria um macrocosmo dos macrocosmos sociais, possuindo uma originalidade e vida própria. Ele considera vários tipos de sociedades globais: a nação, os impérios, as civilizações. No entanto, como afirmaria mais tarde Ortiz, o macrocosmo gurvitchiano não é suficiente para abarcar o planeta como um todo.

No início da década de 80 a discussão sobre globalização ganha corpo nos Estados Unidos. Provavelmente sua posição hegemônica no cenário internacional tenha contribuído para instigar a imaginação dos intelectuais. Vários textos e obras problematizam o tema. Em 83 a Harvard Business Review publica um artigo de Theodore Levitt sobre marketing global. $O$ texto tem grande repercussão, tanto na comunidade acadêmica como no mundo dos

\footnotetext{
"Mestrando em Sociologia Rural da Universidade Federal da Paraiba - Campus Il, Campina Grande-PB.
} 
negócios. Três anos depois, E. Tiryakian publica "Sociology's great leap forward: the challenge of internationalization", onde defende que o ensino da sociologia deveria ser transformado diante da emergência de um mundo globalizado.

Esses dois autores não podem ser considerados como "os pioneiros", mas suas contribuições foram as mais significativas para a emergência da discussão, que tem sido levado a cabo com mais intensidade pelos americanos. Na França, por exemplo, até meados dos anos 80 havia quase que um "silêncio tumular" a respeito do tema globalização, até que Henry Lefebvre, segundo R. Hess, se interessa pelo assunto e se "choca com a indiferença dos franceses pela mundialidade."

A globalizaçăo tem sido tratada por diferentes disciplinas administração, economia, relações internacionais, sociologia, entre outras, o que revela seu caráter multidisciplinar. No entanto, a literatura produzida precisa ser analisada com alguns cuidados. Ela pode ser dividida, pelo que se apreende de quem vem tratando o tema com seriedade, em pelo menos três grupos. $O$ primeiro deles é formado pelos chamados futuristas, que tem como principal representante o americano Alvin Toffler, com suas "ondas de mudança" e seu otimismo quanto a emergência de uma sociedade feliz, marcada pelo domínio da técnica e uma "consciência planetária."

No segundo grupo se inclui, com poucas exceções, a literatura produzida por administradores, consultores de empresas, especialistas em relações humanas e auto-ajuda. Eles estão ganhando verdadeiras fortunas com "receitas" para "uma convivência mais harmônica, eficiente e produtiva" com as mudanças decorrentes do processo de globalização. São técnicas de "energização", "reengenharia", "qualidade individual" e tantas outras. As livrarias estão abarrotadas com esse tipo de literatura.

A literatura que se encaixa no terceiro grupo tem preocupações mais abrangentes e rigores científicos. Se por um lado vê com desconfiança as mudanças que vêm sendo operadas, por outro oferece um arcabouço teórico que estimula a reflexão e o debate sobre a inevitabilidade do processo. $O$ trabalho mais significativo nesse 
campo foi publicado por Adam Schaff, com o respaldo do Clube de Roma. Apesar de sua formação marxista, Schaff, em a "Sociedade Informática" não se prende a dogmas nem a rigidez doutrinária. $\mathbf{E}$ otimista quanto ao futuro. Acredita que a automação da produção e dos serviços levará a um considerável enriquecimento da sociedade e que esta riqueza, ao final, será distribuída, seja qual for o sistema político predominante, com um certo grau de equidade.

A proposta deste trabalho não é discutir a "globalidade" do tema, mas um dos seus muitos aspectos: a mundialização da cultura. No entanto, a meu ver, ficaria incompleto ou descontextualizado sem as considerações históricas pinceladas acima. No capítulo seguinte tentarei problematizar a questão da cultura mundializada, destacando o conjunto de valores, estilos, formas de pensar, que se estende a uma diversidade de grupos sociais vistos até então "como senhores do seu próprio destino."

No último capítulo, já em forma de conclusão, destacarei algumas das prováveis mudanças e conseqüências que a globalização trará para a formação cultural das sociedades. Todas as reflexões aqui "ensaiadas" são resultados da "apropriação" de leituras estimuladas pelo curso "Globalização", ministrado pelo professor Dr. José Bolívar, no Mestrado de Sociologia.

\section{I - CULTURA GLOBALIZADA?}

(o homem cidadão do mundo)

Parece consenso que o mundo das últimas décadas se transformou radicalmente, desafiando os intelectuais a apresentarem respostas para uma gama variada de problemas e questões que se renovam a cada dia. $O$ movimento da globalização ainda intimida às Ciências Sociais, pela sua magnitude. A tradição acadêmica nesta área encontra-se em fase de formação. Os aspectos mais discutidos, até agora, estão mais relacionados à disciplinas como economia e administração. A questão ecológica também tem recebido um tratamento bastante produtivo. No entanto, em nenhuma dessas áreas, há estudos conclusivos; quando muito especulações e "futurismo." 
A conjuntura mundial hoje pode ser resumida da seguinte forma: a aplicação direta da ciência e da técnica à produção revoluciona a base produtiva da sociedade, mundializa o mercado, reduz o papel do Estado nacional e de todas as formas de organização social oriundas do velho modelo. A informática e a robótica, a automação e a telemática levam ao declínio do modelo tayloristafordista da chamada II revolução industrial. A agricultura é revolucionada pela biotecnologia. Os meios de comunicação encurtam distâncias e tendem a homogeneizar culturas, chocando-se, na visão de alguns teóricos críticos da comunicação de massa moderna, com a "contribuição de cada cultura nacional à herança comum da humanidade." O saber e a informação desempenham o papel determinante na nova etapa.

Esse processo, segundo alguns autores, regido pela lei do mercado, tende a tornar descartável o trabalho humano, gera graves problemas ambientais, agrava as desigualdades entre países e regiões, marginalizando de seus benefícios boa parte da população mundial. Contrapondo-se a essa perspectiva pessimista, Adam Schaff, embora reconheça que as mudanças em processo trarão conseqüências econômicas, sociais, políticas e culturais significativas, acredita que a globalização proporcionará a geração de mais riquezas e uma melhor distribuição dessas mesmas riquezas.

Na economia, a globalização se dá, basicamente, por três vias: comércio internacional, investimento e fluxo financeiro. Em outras palavras: trata-se de integrar cada país no mercado internacional abrindo sua economia à concorrência, permitir o acesso de capitais a áreas antes impedidas (privatização) e facilidades para os fluxos financeiros. Para os mais céticos, esse processo se materializa com "uma aguda e feroz concorrência", onde grandes grupos, donos dos recursos materiais e do conhecimento, pressionam os governos, reduzem o poder soberano do Estado e retiram sua capacidade de gerar recursos e investir em políticas públicas de caráter social. Nos países em desenvolvimento os efeitos da globalização, a partir deste ponto de vista, são muito mais dramáticos

Economia à parte, o foco de nossa reflexão é pensar esta realidade mundial tomando como ponto de partida a problemática cultural. Segundo Ortiz, não é uma tarefa fácil, porque a "herança 
intelectual tende a ressaltar os aspectos específicos de cada cultura." $\mathrm{O}$ autor citado distingue, para efeito didático-metodológico, os termos "global" e "mundial." Emprega o primeiro quando se refere a processos econômicos e tecnológicos e reserva ao segundo a especificidade da cultura. Neste sentido, a categoria "mundo" encontra-se articulada a duas dimensões: vincula-se, primeiro, ao movimento de globalização das sociedades, mas significa, também, uma "visão de mundo", um universo simbólico específico à civilização atual. Convive com outras visões de mundo, estabelecendo, entre elas, hierarquias, conflitos e acomodações.

Para Ortiz é mais "convincente" compreender a mundialização como processo e totalidade. Processo que se reproduz e se desfaz incessantemente no contexto das disputas e das aspirações divididas pelos atores sociais, mas que se reveste de uma "dimensão abrangente englobando outras formas de organização social: comunidades, etnias e naçōes." A mundialidade como totalidade aproxima-se da noção de civilização, proposta por Marcel Mauss: conjunto extranacional de fenômenos sociais específicos e comuns a várias sociedades. No entanto, há uma particularidade que deve ser ressaltada: historicamente uma civilização se estendia para além dos limites dos povos, mas se confinava a uma área geográfica determinada; uma cultura mundializada corresponde a uma civilização cuja territorialidade se globalizou.

Embora tenha suas raízes no século XIX o processo de mundialização só se realiza plenamente neste século, mais principalmente, depois da Segunda Guerra, quando vai sofrer saltos e redefinições. $O$ modo de produção industrial, aplicado ao domínio da cultura, tem a capacidade de impulsioná-la no circuito mundial. $O$ que se encontrava restrito aos mercados nacionais, agora se expande. $O$ cinema tem, desde cedo, um papel fundamental para o intercâmbio das imagens. A exploração de gêneros populares, western, aventura, folhetim consagra na tela diferentes estilos, formando uma cultura da imagem que transcende sua origem nacional.

A indústria fonográfica, também, é outro exemplo, só que menos explorado. Com o fonógrafo de thomas Edson e o aprimoramento das técnicas de fabricação de discos, começam a ser forma- 
das grandes companhias no Reino Unido, na Alemanha, na França e nos EUA, que se caracterizam pela sua polítiça de atuação mundial. $\mathrm{O}$ advento do rádio e da televisão fortalece o circuito de trocas culturais com dimensões mundiais. Os países do Terceiro Mundo também são integrados nesse contexto pelos médias, que crescem numa proporção fantástica.

A base técnica sobre a qual se apoiam as mensagens é também responsável por um tipo de civilização que se mundializa. Filmes, anúncios publicitários, música popular e séries televisivas são formas de expressão que circulam no seu interior, independente de suas origens.

Os teóricos da comunicação sublinham que as inovações tecnológicas têm uma evidente influência capital na mundialização da cultura, formando a infra-estrutura material para que ela se consolide. Redes de computadores, fax, satélites possibilitam a comunicação a distância, "favorecendo o desenvolvimento das cadeias televisivas planetárias e das firmas globais."

Com a microeletrônica, a codificação e a transmissão das mensagens adquirem um caráter de transversalidade. Som, imagem e texto são convertidos em bits e reconvertidos em seus respectivos conteúdos quando chegam a seus destinos. A televisão já não está mais conectada apenas aos diversos canais, mas a tela faz o papel de visor integrando os cassetes, os jogos eletrônicos e o computador. A tecnologia de ponta confere um "substrato material" à modernidade-mundo, na visão de Chesnaux, articulando suas partes constituintes. "Um evento remoto torna-se próximo, e o que nos rodeia pode estar afastado."

Nas suas reflexões sobre a mundialização da cultura Renato Ortiz faz uma advertência: apesar do desenvolvimento espetacular das tecnologias, não devemos imaginar que vivemos em um mundo sem fronteiras, como se o espaço estivesse definitivamente superado pela velocidade do tempo. Seria mais correto dizer que a modernidade, ao romper com a geografia tradicional, cria novos limites. Se a diferença entre o Primeiro e o Terceiro Mundo é diluída, outras surgem no seu interior, agrupando ou excluindo pessoas. 


\section{II - O QUE ESPERAR DA MUNDIALIZAÇÃO \\ (a formação do homem universai)}

Para Adam Schaff a sociedade informática vai escrever "uma nova página na história da humanidade," dando um grande passo no sentido da materialização do velho ideal dos grandes humanistas - o do homem universal. Essa universalidade tem dois sentidos: o de sua formação global, que lhe permitirá fugir do estreito caminho da especialização unilateral; e o de se libertar do enclausuramento numa cultura nacional, para converter-se em cidadão do mundo no melhor sentido do termo. Para efeito de precisão conceitual, o termo sociedade informática em Schaff significa uma sociedade assentada em bases técnicas, no conhecimento, na informação e num mercado global. Em outras palavras: uma sociedade formada por relações "mundializadas."

Schaff entende cultura como a totalidade dos produtos materiais e espirituais do homem em um período determinado e em uma determinada nação (cultura nacional), ou no sentido mais amplo, abarcando a totalidade do gênero humano (cultura universal), ou, ainda, no sentido de uma parte isolada da humanidade em escala supranacional. É a partir deste conceito que ele reflete sobre as implicações e consequências sociais, para a cultura, dos processos de globalização. Segundo ele, há três esferas de problemas que precisam ser consideradas: a) difusão da cultura; b) difusão da cultura supra-nacional; c) difusão de novos modelos de personalidade e de um novo caráter social dos homens, que estão em conexão com as duas primeiras questões.

Segundo Schaff, a sociedade informática cria novas possibilidades para a difusão da cultura. $O$ rádio, com o advento do transístores, leva aos lugares mais remotos não só notícias, mas também a música, o teatro, a literatura. A televisão, por sua vez, não só amplia os efeitos da palavra falada como permite a transmissão de outros efeitos estéticos não verbais - obras de artes, paisagens de outros países, danças - e de novos valores educativos - filmes científicos, documentários, etc. Essas inovações estão sendo complementadas com um outro e mais moderno meio denominado de "autômatos falantes", que segundo Schaff, vai revolucionar o ensino. Os "autômatos" transmitem conhecimento em diversos cam- 
pos e estão programados para estabelecer diálogos com o estudante.

$O$ avanço da informática, no campo específico da cultura, pode proporcionar: o alívio da carga de memória humana (os computadores tem supermemória) ; rapidez em operações combinatórias; a idealização de novos métodos de conhecimento humano em muitas disciplinas; e a agilização do aprendizado e da verificação do conhecimento, através do diálogo estabelecido com a máquina.

Schaff levanta a seguinte questão: embora a difusão da cultura em conseqüência da sociedade informática seja evidente, o problema do tipo de cultura nacional e supra-nacional a ser alcançado como resultado desse processo de mudanças é muito mais complexo e controvertido. Afirma, por exemplo, que a cultura de uma sociedade desenvolvida é sempre tanto nacional quanto supranacional, o que, a seu ver, eqüivale dizer que, ao lado de elementos específicos de uma cultura de uma nação determinada, há elementos comuns a grupos de nações ou universais. A principal tendência que se configura neste caso específico, é o rompimento das barreiras do provincianismo das culturas locais. A tendência a internacionalização da cultura é progressiva e corresponde ao desenvolvimento das relações humanas em todo mundo e em todos os aspectos. A globalização eliminará "todas as barreiras artificiais entre as culturas."

Última questão: a propagação da cultura e a expansão da cultura supra-nacional enriquecem a personalidade humana, fazem com que os seres humanos ascendam a um nível superior de cultura e, finalmente, mudam os modelos de referência pessoal e o caráter social. Raramente o homem, afirma Schaff, se dá conta de até que ponto seus atos conscientes são influenciados e, inclusive, determinados por fatores que estão além de sua consciência, ainda que esses fatores sejam inerentes à sua personalidade e à sua mentalidade e, sobretudo, a seu caráter social. A sociedade informática cria um "homem novo" , "o homem universal", aquele que estará munido de uma instrução completa e em condições de mudar de profissão e também de posição no interior da organização social do trabalho. A realização dessa "idéia", segundo Schaff, poderá ser alcançada graças à educação permanente e à técnicas de 
informação sempre mais eficientes. Estes dois fatores, tornarão possíveis a materialização de duas utopias: a eliminação da diferença entre trabalho manual e trabalho intelectual e entre trabalho no campo e trabalho nas cidades.

O primeiro problema, garante, será resolvido pela superação do trabalho manual pela automação e pela robótica. A ciência, na sociedade mundializada, é força produtiva primária e a produção terá necessidade, além dos autômatos, de técnicos especializados e de engenheiros. É o fim da classe operária. Quanto ao segundo problema, Schaff afirma que as tecnologias disponíveis de transportes, meios de informações, novas técnicas de produção tenderão a tornar a vida no campo muito mais confortável e atraente, com ares urbanísticos, mas as diferenças, em termos de trabalho, tenderão a continuar.

Mesmo assim afirma: estamos, portanto, diante de uma diferença específica, mas o caminho que leva à formação do homem universal não está obstruído, pois a transformação dos interesses e das capacidades provocarão maior mobilidade entre as áreas urbanas e as rurais e vice-versa.

\section{PALAVRAS FINAIS}

Se há algum mérito no presente trabalho é o de ter compilado e se apropriado de idéias e questões de autores que estão pensando, em diversas áreas, os efeitos da globalização. A parte introdutória do primeiro capítulo foi uma tentativa de resumir o conteúdo aplicado nas aulas do curso sobre o tema que foi ministrado pelo professor Bolivar. O que se seguiu depois, foram leituras e apontamentos que estão sendo feitos com vistas a contextualização da problemática proposta como plano de estudo para o Mestrado em Sociologia.

Optei pelo estilo direto, deixando as referências para o final, tornando, assim, o texto "mais limpo", mesmo contrariando algumas normas acadêmicas. Embora rígidas do ponto de vista teórico, na prática, acredito, deve haver algum nível de flexibilização.

Não estou entre os otimistas quanto aos efeitos da globaliza- 
ção, nem entre os pessimistas. Vejo com preocupação a questão do desemprego, da homogeneização da cultura, da redução do poder do estado Nacional, das identidades, da concorrência desenfreada. Não acredito numa sociedade sem o mínimo de controle do Estado sobre as atividades econômicas. $\mathrm{O}$ mercado, ao longo da história, não tem se mostrado um bom regulador das relações sociais e de produção. As tendências em curso, apontam para o agravamento do processo de exclusão das economias em desenvolvimento. Não tenho ainda uma opinião formada e definida a esse respeito, mas avaliando do ponto de vista ético, não nos parece justo que esse processe inevitável de mudança traga facilidades e felicidade para uns poucos e miséria e sofrimento para a grande maioria.

Especificamente sobre a questão cultural, acho que a cultura de cada país deve ser respeitada, o que não significa dizer que, a pretexto de preservá-la, a comunidade nacional se feche. Pelo contrário, a mundialização, para usar a terminologia de Ortiz, oferece enormes possibilidades de trocas culturais, sem prejuízo das tradições. Aperfeiçoamentos são inevitáveis. Vejo um grande potencial de aprendizado, a partir do aproveitamento das modernas técnicas de difusão.

A sociedade informática, como afirma Schaff, não garante o paraíso. $O$ apelo à ação talvez seja a contribuição mais significativa de seu trabalho e pode ser satisfeito com a condição de que a própria sociedade desempenhe um papel ativo no processo de educação do "homem novo."

\section{REFERÊNCIAS BIBLIOGRÁFICAS}

CASTELS, M. (org.) High technology, space and society, Beverly Hills, Sage Publications, 1985.

CHESNAUX, J. La Modernité-monde, Paris, La Découvert, 1989.

MACLUHAN, M; POWERS, B. R. The global village, Oxford, Oxford Universitty Press, 1989.

SCHAFF, Adam. Sociedade Informática, S. Paulo, Unesp/Brasiliense, 1991.

MATTA, Fernando Reyes (Org.). A informação na nova ordem internacional. Paz e Terra, São Paulo, 1980.

ÁVILA, Carlos Rodolfo Améndola. A teleinvasāo. Cortez Editora, S.Paulo, 
1982.

THOMPSON, John B. Ideologia e cultura moderna. Vozes, Petrópolis - RJ, 1995.

ORTIZ, Renato. Mundialização da cultura. Brasiliense, $2^{a}$ Edição, São Paulo, 1994.

GURVITCH, G. La Vocation actualle de la sociologie, Paris, PUF, 1950. 